\title{
Subdivision of flagellar region III of the Escherichia coli and Salmonella typhimurium chromosomes and identification of two additional flagellar genes
}

\author{
Ikuro Kawagishi, $†$ Volker Müller, $\ddagger$ Andrew W. Williams, Vera M. Irikura $\uparrow$ and \\ ROBERT M. MACNAB*
}

Department of Molecular Biophysics and Biochemistry, Yale University, New Haven, CT 06511, USA

(Received 21 January 1992; accepted 6 March 1992)

\begin{abstract}
The many genes involved in flagellar structure and function in Escherichia coli and Salmonella typhimurium are located in three major clusters on the chromosome: flagellar regions I, II and III. We have found that region III does not consist of a contiguous set of flagellar genes, as was thought, but that in $E$. coli there is almost $7 \mathrm{~kb}$ of DNA between the filament cap gene, fiD, and the next known flagellar gene, fiE; a similar situation occurs in $S$. typhimurium. Most of this DNA is unrelated to flagellar function, since a mutant in which $5.4 \mathrm{~kb}$ of it had been deleted remained fully motile and chemotactic as judged by swarming on semi-solid agar. We have therefore subdivided flagellar region III into two regions, IIIa and IIIb. The known genes in region IIIa are ftiABCD, all of which are involved in filament structure and assembly, while region IIIb contains genes ftiEFGHIJKLMNOPQR, all of which are related to formation of the hook (basal-body)-complex or to even earlier assembly events. We have found that fitD, the last known gene in region IIIa, is immediately followed by two additional genes, both necessary for flagellation, which we have designated $f i S$ and $f i t$. They encode small proteins with deduced molecular masses of about $15 \mathrm{kDa}$ and $14 \mathrm{kDa}$, respectively. The functions of FliS and FliT remain to be determined, but they do not appear to be members of the axial family of structural proteins to which FliD belongs.
\end{abstract}

\section{Introduction}

The flagellar gene systems of Escherichia coli and Salmonella typhimurium (subscripts $\mathrm{E}$ and $\mathrm{S}$ are used to distinguish $E$. coli and $S$. typhimurium genes or gene products) are closely similar and quite complex, consisting of over 40 genes organized into a regulon with a master operon and at least 14 subsidiary operons whose length varies from one to nine genes (Komeda, 1986; Kutsukake et al., 1988). Extensive mapping studies have established that they are tightly clustered on the

\footnotetext{
* Author for correspondence. Tel. (203) 432 5590; fax (203) 432 5175; email rmacnab@yalevm.bitnet.

† Present address: Department of Molecular Biology, Nagoya University, Nagoya, Japan.

$\ddagger$ Present address: Institut für Mikrobiologie, Georg-August Universität Göttingen, Göttingen, Germany.

Tी Present address: Department of Biochemistry \& Molecular Biophysics, Columbia University, New York, NY 10032, USA.

The nucleotide sequence data reported in this paper have been submitted to GenEMBL $\left(f i D_{\mathrm{S}}\right.$, accession no. X51740) and GenBank (fiDST $T_{\mathrm{E}}$, accession no. M85240; fiST $T_{\mathrm{S}}$, accession no. M85241).
}

chromosome (Fig. 1) (for references, see Macnab, $1987 a, b$ ). One major cluster (flagellar region I) is located at around $24 \mathrm{~min}$. The other two major clusters (regions II and III) are located at around 40-43 $\mathrm{min}$ and are separated by about $22 \mathrm{~kb}$ of DNA (estimated from the restriction data of Kohara et al., 1987) that includes genes unrelated to flagellar function, such as $u v r C$. [In $S$. typhimurium there is also a small cluster of three genes at $56 \mathrm{~min}$, which includes the phase-2 flagellin gene and related control genes (Yamaguchi et al., 1984).]

Within a given region it was believed from detailed genetic analysis that only flagellar, motility and chemotaxis genes exist. This belief has since been supported by molecular analysis in the cases of region I of $S$. typhimurium (Jones et al., 1989; Homma et al., 1990a, b; Gillen \& Hughes, 1991; K. Kutsukake, personal communication) and region II of $E$. coli (Krikos et al., 1983; Dean et al., 1984; Mutoh \& Simon, 1986; Stader et al., 1986; Bartlett et al., 1988; Kim, 1989; Kofoid \& Parkinson, 1991), which have been cloned and sequenced in their entirety.

Region III has also been extensively characterized. In 


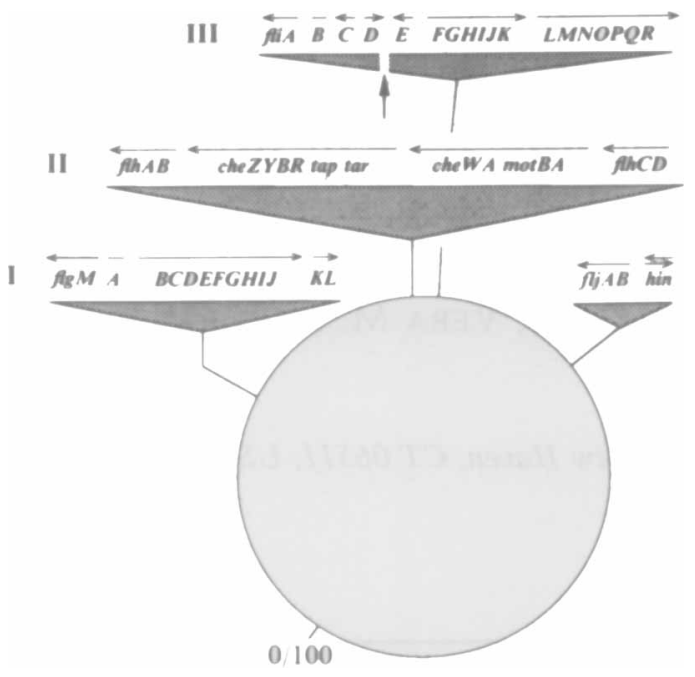

Fig. 1. Flagellar and related genes of E. coli and S. typhimurium, and their organization on the chromosome. They fall into three major regions, I, II and III. Each of these was thought to consist of a contiguous set of genes, all in some way connected with flagellation, motility or chemotaxis, but the present study has shown that region III has a large disruption between fiD and fiE (vertical arrow). 0/100 (min) represents the arbitrarily assigned start and end of the circular map at the thr locus (Sanderson \& Roth, 1988; Bachmann, 1990). Operons are shown by overlining, with an arrowhead indicating the polarity where this is known. $S$. typhimurium has a small fourth region, fljAB hin; the tap gene is absent in $S$. typhimurium, and $f i B$ has not been established for $E$. coli.

$S$. typhimurium it contains 18 genes, fiABCDEFGHIJKLMNOPQR, in that order. [In E. coli, the fiiB gene (which encodes an enzyme for methylating flagellin; Konno et al., 1976) has not been established.] $f i C_{\mathrm{S}}$ (the structural gene for the filament protein, flagellin) was the first flagellar gene to be sequenced (Joys, 1985; Kuwajima et al., 1986), and subsequently $f i A, f i B, f i D$, and all of the genes from $f i F$ through $f i R$ were sequenced in at least one of the two species, and in many cases in both (Kuo \& Koshland, 1986; Jones et al., 1989; Kihara et al., 1989; Malakooti et al., 1989; Homma et al., 1990a; Ohnishi et al., 1990; Vogler et al., 1991; K. Kutsukake, personal communication; R. M. Macnab, unpublished data; $P$. Matsumura, personal communication).

This left $f i E$ as the last known region III gene to be characterized. In preparing to analyse it, we found that restriction sites for plasmids containing DNA to the right of $f i D$ and for plasmids containing DNA to the left of $f i F$ - all of which were expected to contain $f i E$ information - could not be reconciled. This was true of both $E$. coli and $S$. typhimurium, and raised the question of whether these three genes were in fact contiguous.

The earlier literature contains several observations concerning flagellar region III that could not be fully interpreted with the information available at the time, but are consistent with there being additional DNA in the vicinity of $f i C-f i E$. These observations include the occurrence of deletion endpoints between known genes (Yamaguchi et al., 1972; Silverman \& Simon, 1974), disparate co-transduction frequencies (Silverman \& Simon, 1973a), and the unexpectedly large size of a cloned insert of the region (Silverman et al., 1976).

We have therefore re-examined the arrangement of genes within this part of flagellar region III, and found that there is indeed a substantial extent of DNA between $f i D$ and $f i E$, most of which can be deleted without affecting flagellar function. We describe these results here, along with a characterization of the region between $f i D$ and the start of this non-flagellar region. The detailed characterization of $f i E$ has been described elsewhere (Müller et al., 1992).

fliD constitutes a transcriptional unit separate from all other known flagellar genes, and was thought to be monocistronic. However, since it was originally discovered using mutants generated by Mu phage insertion (Komeda et al., 1980), and no complementation analysis of missense mutants was described, the data do not preclude the possibility of additional genes in the operon. We have in fact noted previously (Homma et al., 1990a) that the sequence immediately beyond the $3^{\prime}$ end of $f i D_{\mathrm{S}}$ suggests the existence of another gene within the same operon. We have now established that $f i D$ is followed by two additional flagellar genes located just before the nonflagellar region.

\section{Methods}

Bacterial strains. E. coli strains used in this study are listed in Table 1. JA 1 1, kindly supplied by $J$. Asaka, is a non-revertible $f i C_{E}$ mutant, in which the $5^{\prime}$ half of the $f i C_{\mathrm{E}}$ coding region has been deleted and replaced by the kanamycin resistance gene (J. Asaka, personal communication). We refer to this genotype as $\Delta f i C_{\mathrm{E}}:: k a n$.

Plasmids. pIK 1001 and its derivatives are pBR322-based plasmids with an $E$. coli chromosomal fragment containing the $f i C-F_{\mathrm{E}}$ region; they are described in Results. pMH83 and its derivatives are pBR322based plasmids with an $S$. typhimurium fragment containing $f i C_{\mathrm{s}}, f i D_{\mathrm{S}}$ and about $3 \mathrm{~kb}$ beyond (Homma et al., 1985). pOYAl is pUC119-based and contains a $6.7 \mathrm{~kb}$ EcoRI fragment of $S$. typhimurium region III chromosomal DNA (Müller et al., 1992). Plasmid pUC4K, carrying a kan gene cassette, was obtained from Pharmacia/LKB.

Chemicals and enzymes. All chemicals and enzymes were obtained from standard commercial sources. Antibiotics were used at the following concentrations: ampicillin, $50 \mu \mathrm{g} \mathrm{ml}^{-1}$; kanamycin, $25 \mu \mathrm{g}$ $\mathrm{ml}^{-1}$; tetracycline, $10 \mu \mathrm{g} \mathrm{ml}^{-1}$. Sal I linker, and EcoRI and XhoI linkers, were purchased from Pharmacia/LKB and New England Biolabs, respectively. Random primer and $\left[\alpha^{-32} \mathrm{P}\right] \mathrm{dCTP}\left[6000 \mathrm{Ci} \mu \mathrm{mol}^{-1}(222\right.$ TBq $\left.\mu \mathrm{mol}^{-1}\right)$ ] were purchased from Boehringer-Mannheim and Amersham, respectively.

Manipulation of DNA. Isolation of chromosomal and plasmid DNA, manipulation of DNA, and transformation of host cells were all carried out by standard procedures, mainly based on Sambrook et al. (1989). 
Table 1. E. coli strains used in this study

\begin{tabular}{|c|c|c|}
\hline Strain & Relevant genotype & Reference \\
\hline CES200 & $\mathrm{F}^{-} \operatorname{recB} 21 \mathrm{rec} C 22 \mathrm{sbcB} 15 \mathrm{sbcC} h s d R$ & Wyman et al. (1985) \\
\hline DH $5 \alpha$ & $\mathrm{F}^{-} \mathrm{recAl} \mathrm{fla}^{+}$ & Gibco/BRL \\
\hline JA11 & $\mathrm{F}^{-} \Delta f i C_{\mathrm{E}}::$ kan hsdR hsdM & J. Asaka, personal communication \\
\hline MS111 & fliF of MS1350 & Silverman \& Simon $(1973 b)$ \\
\hline RP4191 & fliE of W3623(ג) & Kondoh (1977); Parkinson et al. (1983) \\
\hline RP4501 & fiiG of RP437 & Parkinson et al. (1983) \\
\hline YK1101 & fliD of YK410 & Komeda et al. $(1980,1984)$ \\
\hline YK4104 & $f i A$ of YK410 & Suzuki \& Komeda (1981) \\
\hline YK4146 & flic of YK 410 & Komeda et al. $(1980,1984)$ \\
\hline
\end{tabular}

DNA sequencing and sequence analysis. DNA sequencing was performed on fragments cloned into M13 phage using the dideoxy chain-termination method (Sanger et al., 1977). Both strands were sequenced in their entirety. Deletions of restriction fragments were obtained by ExolII digestion using standard protocols (Sambrook et al., 1989). Custom primers were synthesized by a facility in the Department of Chemistry, Yale University. Routine sequence manipulations were carried out using the personal computer package DNANAL YZE (Greg Wernke, University of Cincinnati Medical School). Sequence comparisons were made against the NBRF protein database (version 24.0; March, 1990) using the FASTA algorithm and the GenBank DNA database (version 67.0; March, 1991) using the TFASTA algorithm.

Motility assay. Motility of cells was detected as swarming on semisolid agar plates (containing antibiotics where appropriate) at $30^{\circ} \mathrm{C}$. Motility and flagellation were also observed by high-intensity darkfield light microscopy (Macnab, 1976).

Minicell analysis. Gene products were identified by radiolabelling of minicells carrying plasmids of interest, by the method described by Homma et al. (1985).

DNA hybridization. For preparing DNA probes, restriction fragments were isolated, denatured, and labelled with $\left[\alpha-{ }^{32}\right.$ P $]$ dCTP by means of random-primed DNA synthesis (Feinberg \& Vogelstein, 1983). Chromosomal DNA was isolated, digested with restriction enzyme, subjected to $0.7 \%$ agarose gel electrophoresis, and transferred onto nitrocellulose membrane (Sambrook et al., 1989). Hybridization with radiolabelled primer was carried out under stringent conditions (incubated in $0.75 \mathrm{M}-\mathrm{NaCl}, 75 \mathrm{~mm}$-sodium citrate, Denhardt's reagent, $50 \%$, v/v, formamide, $0.1 \%$ SDS, $10 \%$ dextran sulphate and $0.1 \mathrm{mg}$ salmon sperm DNA ml-1 $42^{\circ} \mathrm{C}, 12 \mathrm{~h}$; washed in $15 \mathrm{mM}-\mathrm{NaCl}, 1.5 \mathrm{mM}-$ sodium citrate, $0 \cdot 1 \% \mathrm{SDS}, 60^{\circ} \mathrm{C}, 2 \mathrm{~h}$ ) and detected by autoradiography.

\section{Results}

\section{Cloning of the fliC-F region of $E$. coli}

Restriction mapping data and other evidence had led us to suspect that $f i D$ and $f i E$ might be separated by a considerable distance (see Introduction). We elected to investigate the issue initially in $E$. coli rather than $S$. typhimurium, because it had already been established that the entire set of genes from $f i C_{\mathrm{E}}$ through $f i F_{\mathrm{E}}$ lay within a single $E c o R I$ restriction fragment (Silverman $e t$ al., 1976).
As the source of the chromosomal DNA, we used an E. coli $\mathrm{K} 12$ derivative, JA11, which is wild-type for all flagellar genes except $f l C_{\mathrm{E}}$; that gene has been altered by a 5'-deletion and insertion of a kan cassette at the site of the deletion $\left(\Delta f i C_{\mathrm{E}}:: k a n\right)$ (J. Asaka, personal communication). The DNA was digested with EcoRI and ligated into plasmid pBR322 and the recombinant plasmid pool used to transform the recA strain DH5 $\alpha$. An Ampr ${ }^{r} a n^{r}$ Tet $^{r}$ transformant was shown to contain a plasmid with a $14 \mathrm{~kb}$ EcoRI insert. This plasmid, designated pIK 1001 (Fig. 2), complemented $f i D_{\mathrm{E}}, f i E_{\mathrm{E}}$ and $f i F_{\mathrm{E}}$ mutants, but not $f i A_{\mathrm{E}}, f i C_{\mathrm{E}}$ or $f i G_{\mathrm{E}}$ mutants. Restriction analysis of pIK 1001 yielded a map (Fig. 2) that was consistent with existing information in the vicinity of $f i D_{\mathrm{E}}$ and fiF $_{\mathrm{E}}$ (Bartlett \& Matsumura, 1984; G. Kuwajima, personal communication), and indicated a large distance between the two genes. We constructed and characterized various derivatives from pIK1001, some of which are shown in Fig. 2; the restriction and complementation data obtained were again consistent with existing information. Therefore we concluded that, as expected, pIK 1001 carries a fragment with the complete $f i C-F_{\mathrm{E}}$ region of the chromosome (except for the deleted $5^{\prime}$ portion of $f l i C_{\mathrm{E}}$ ). A derivative plasmid, pIK 1007 (described in more detail below), lacked a $5.4 \mathrm{~kb} M l u I-$ $X b a I$ fragment but nonetheless complemented $f i D_{\mathrm{E}}$, $f i E_{\mathrm{E}}$ and $f i F_{\mathrm{E}}$ mutants (Fig. 2). Thus the existence of an intervening region in the vicinity of $f i E_{\mathrm{E}}$ was confirmed. Plasmid pIK 1004 (which lacked all of the left-hand part of the insert except for a small portion of $f i D_{\mathrm{E}}$, but retained the right-hand part) complemented $f i E_{\mathrm{E}}$ and $f i F_{\mathrm{E}}$ mutants, proving that $f i E_{\mathrm{E}}$ lies close to $f i F_{\mathrm{E}}$ to the right of the intervening region. This has now been further proved by a detailed analysis of the $f i E_{\mathrm{E}}$ gene (Müller et al., 1992).

A similar situation exists in S. typhimurium. Plasmid pOYAl (Müller et al., 1992) contains a $6.7 \mathrm{~kb}$ EcoRI fragment of $S$. typhimurium chromosomal DNA that begins at bp 532 of $f l i D_{\mathrm{S}}$, and ends with the complete $f l i E_{\mathrm{S}}$ gene and the first $74 \mathrm{bp}$ of $f i F_{\mathrm{s}}$. The known extents of the partial $f i D_{\mathrm{S}}$ sequence, the complete $f i E_{\mathrm{S}}$ sequence, and 


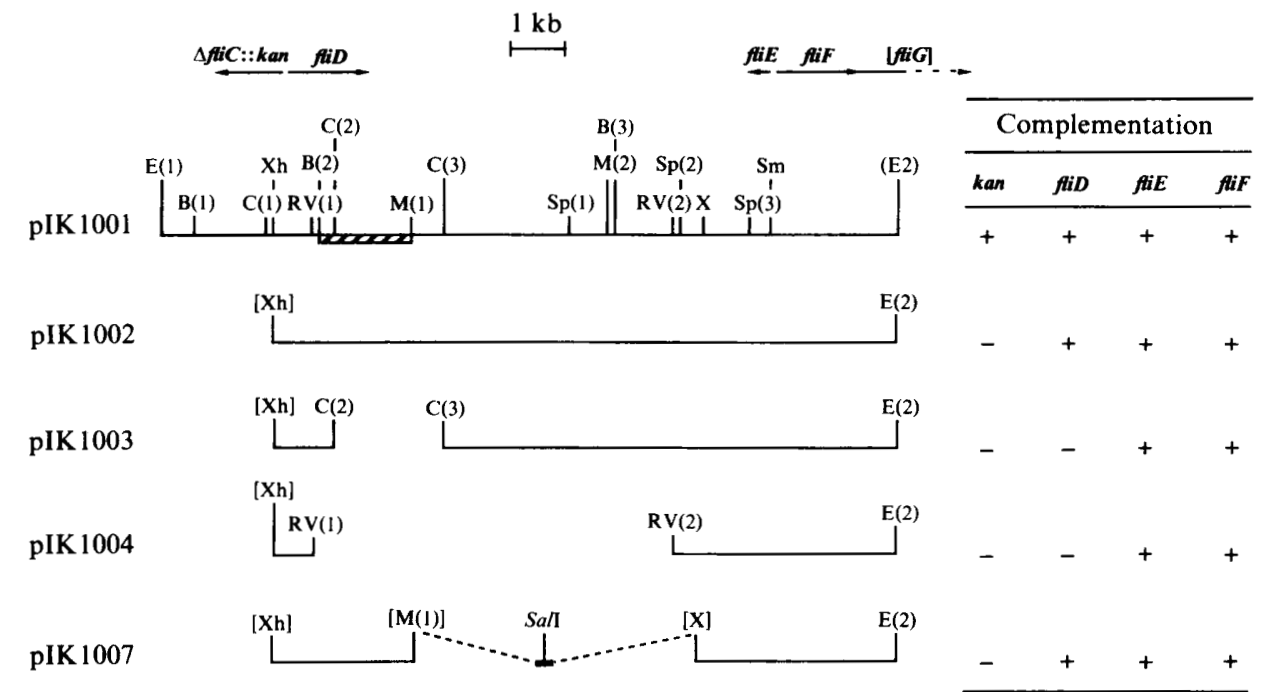

Fig. 2. Restriction map and complementation properties of plasmid pIK 1001 and deletion derivatives thereof. pIK 1001 contains an $E c o$ R I fragment of $E$. coli DNA from flagellar region III that spans the genes from $f i C_{\mathrm{E}}$ through $f i F_{\mathrm{E}}$ and part of $f i G_{\mathrm{E}}$. The approximate location of $f l i E_{\mathrm{E}}$ close to $f i F_{\mathrm{E}}$ was established by the complementation properties of pIK 1004; its exact location and its orientation has since been established by sequence analysis (Müller $\mathrm{et} \mathrm{al}$., 1992), $\mathrm{fli}_{\mathrm{E}}$ has been inactivated by partial deletion and by insertion of a $k a n$ gene cassette. Restriction sites are indicated as follows: B, BamHI; C, ClaI ; E, EcoRI; M, MluI; RV, EcoRV; Sm, SmaI; Sp, SphI; X, $X b a I ; X h, X h o I ;$ multiple instances of a site are indicated by the numbers in parentheses; where a site has been altered, it is shown in brackets. pIK 1007 contains a Sall linker. The BamHI-MluI fragment (hatched box) was used for sequencing the $3^{\prime}$ end of $f i D_{\mathrm{E}}$ and the region downstream.

the partial $f i F_{\mathrm{S}}$ sequence indicate a distance of about $5 \cdot 0$ $\mathrm{kb}$ between $f i D_{\mathrm{S}}$ and $f i E_{\mathrm{S}}$.

\section{Construction of a mutant with a deletion in the intervening region}

At this point, we had established that in region III there was a large distance between two flagellar genes, $f i D$ and $f i E$, that had been thought to be adjacent. The next question was whether the intervening DNA consisted of previously unrecognized flagellar genes, or whether it was unrelated to flagellar function. To answer this, we needed to construct by recombination a strain with the region deleted from its chromosome.

We wished to use the kanamycin resistance (kan) gene as a selectable marker for the chromosomal replacement. The kan insert in $f i C_{\mathrm{E}}$ of pIK 1001 was first inactivated by excising the DNA from a SalI site within the vector to a XhoI site in the kan gene, and ligating the compatible cohesive ends. The resulting plasmid pIK1002 (Fig. 2) was then digested with $M l u I$ and $X b a I$, filled with Klenow fragment, and ligated with T4 DNA ligase in the presence of a SalI linker to produce plasmid pIK1007, in which $5.4 \mathrm{~kb}$ of the intervening region had been deleted. A $1.3 \mathrm{~kb}$ kan gene cassette from pUC4K was then inserted into the $S a l I$ site to give plasmid pIK1007K (Fig. 3a).
For a control in which a known flagellar gene was deleted and the recombinant strain should therefore be non-flagellate, pIK $1003 \mathrm{~K}$ was constructed as follows. Plasmid pIK 1003, derived from pIK 1002, lacks a $1.8 \mathrm{~kb}$ $C l a \mathrm{I}$ fragment starting about $0.8 \mathrm{~kb}$ after the start of $f i D_{\mathrm{E}}$ and as a result fails to complement a $f i D_{\mathrm{E}}$ mutant (Fig. 2). An AccI-digested kan gene cassette was then inserted into the unique ClaI site of pIK 1003 to give plasmid pIK1003K (Fig. 3b).

The deleted versions were then transferred onto the $E$. coli chromosome. First, a motile clone of the rec- $B C_{\mathrm{E}}$ $s b c B_{\mathrm{E}}$ strain CES200 was selected and named IK20. IK20 was transformed with pIK1007K DNA (Fig. 3a) that had been linearized by cutting at the unique EcoRV site, which lies within $f i D_{\mathrm{E}}$. Medium-size, $\mathrm{Kan}^{\mathrm{r}}$ colonies were picked and tested for ampicillin resistance and motility. Of $24 \mathrm{Kan}^{\mathrm{r}}$ transformants tested, all were $\mathrm{Amp}^{\mathrm{s}}$, lacked covalently-closed circular DNA when checked by rapid small-scale preparation of plasmid DNA, and swarmed on semi-solid agar plates as rapidly as their wild-type parent, IK20. One clone, IK27, was saved and characterized further. It was found to be well-flagellated and vigorously motile.

IK20 was also transformed with pIK1003K DNA (Fig. $3 b$ ) linearized by cutting at the unique $N d e$ I site in the vector. Again 24 out of $24 \mathrm{Kan}^{\mathrm{r}}$ clones tested were Amp ${ }^{5}$ but, as expected from homologous recombination 
(a)

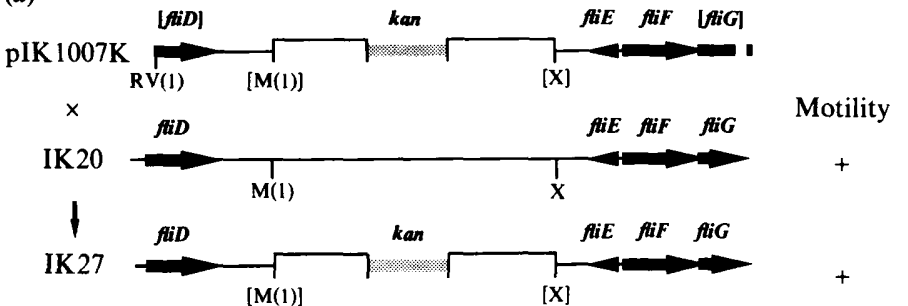

(b)

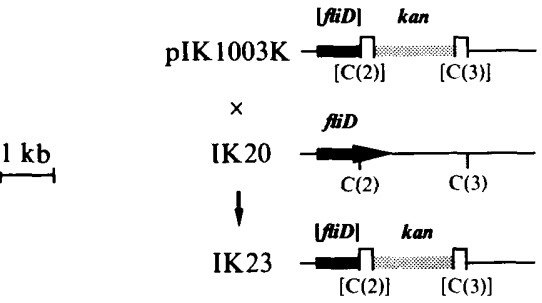

M

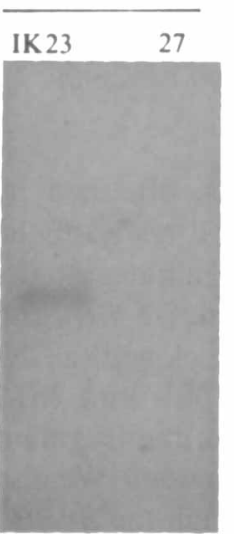

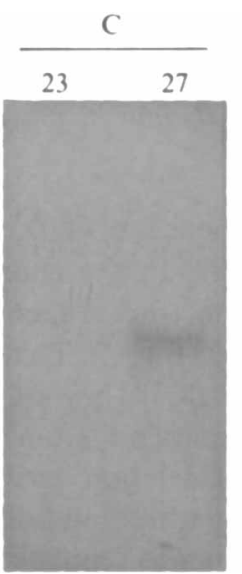

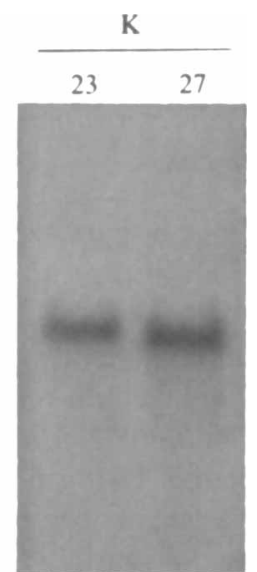

Fig. 4. DNA hybridization of EcoRI digests of chromosomal DNA from strains IK23 and IK27 (Fig. 3). Probes are indicated as: M, chromosomal MluI fragment in intervening region; C, chromosomal ClaI fragment extending from $f i D_{\mathrm{E}}$ into intervening region; $\mathrm{K}$, kanamycin resistance gene.

of a defective $f i D_{\mathrm{E}}$ allele, they were non-motile. One clone, IK23, was saved for further analysis.

DNA hybridization confirmed that IK23 and IK27 had the desired deletions and kan gene insertion. Chromosomal DNA was digested with EcoRI and subjected to hybridization using three different radiolabelled DNA probes: (i) probe C, the $1.8 \mathrm{~kb}$ ClaI(2)ClaI(3) fragment of pIK 1002 containing the $3^{\prime}$ region of $f i D_{\mathrm{E}}$ that had been deleted in pIK 1003; (ii) probe $\mathrm{M}$, the $3.5 \mathrm{~kb} M l u \mathrm{I}(1)-M l u \mathrm{I}(2)$ fragment of pIK 1002, representative of the intervening region deleted in pIK 1007; and (iii) probe $\mathrm{K}$, a $1.3 \mathrm{~kb}$ EcoRI fragment of pUC4K
Fig. 3. Strategy for testing by chromosomal replacement whether the intervening region between $f i D_{\mathrm{E}}$ and $f i E_{\mathrm{E}}$ is needed for flagellar function. (a) pIK $1007 \mathrm{~K}$ is a kan insertion derivative of plasmid pIK 1007 , which has had about $75 \%$ of the intervening region deleted (Fig. 2), from the first $M l u I$ site to the $X b a I$ site; it was linearized and used to transform and recombine with the chromosome of strain IK20, to give strain IK27. (b) A similar procedure was used with a control plasmid pIK1003K (a derivative of plasmid pIK 1003, which has $f i D_{\mathrm{E}}$ and its $3^{\prime}$ flanking region deleted) to give strain IK23. Motility of the parental and recombinant strains is shown at the right, and demonstrates that the deleted region in IK 27 is unrelated to flagellation and motility. containing the kan gene. Under stringent hybridization conditions, an EcoRI fragment of the IK 23 chromosome should be detected by probes $M$ and $K$ but not $C$, while a fragment of the IK 27 chromosome should be detected by probes $C$ and $K$ but not $M$. The results (Fig. 4) conformed to the expected pattern, demonstrating that the strains had the intended chromosomal replacements.

We conclude that the region between MluI(1) and $X b a I$ of pIK 1001 does not contain any flagellar genes. IK 27 grew in minimal medium at the same rate as its parent, even after serially subculturing for $7 \mathrm{~d}$; thus the deleted region does not contain any genes that are essential for viability under these conditions. Normal growth was also observed with a $S$. typhimurium mutant, SJW 1673 (Kihara et al., 1989), which has a large deletion from $f i C_{\mathrm{S}}$ through $f i E_{\mathrm{S}}$ and so has lost not only several flagellar genes, but also all of the non-flagellar region.

\section{Characterization of the region immediately beyond fliD}

The results described thus far allowed us to say that most of the DNA between $f i D$ and $f i E$ was not needed for flagellation, but left the DNA immediately beyond $f i D$ uncharacterized in that regard.

The recombinant mutant IK23 (Fig. $3 b$ ) has a chromosomal deletion that extends from within $f i D_{\mathrm{E}}$ to beyond the $M l u I$ site that defines the left boundary of the known non-flagellar region. It could therefore be used as a host in complementation experiments in which various plasmids containing the homologous region of $S$. typhimurium DNA were used as the donor, and transformants were checked for their ability to swarm on semisolid agar plates. 


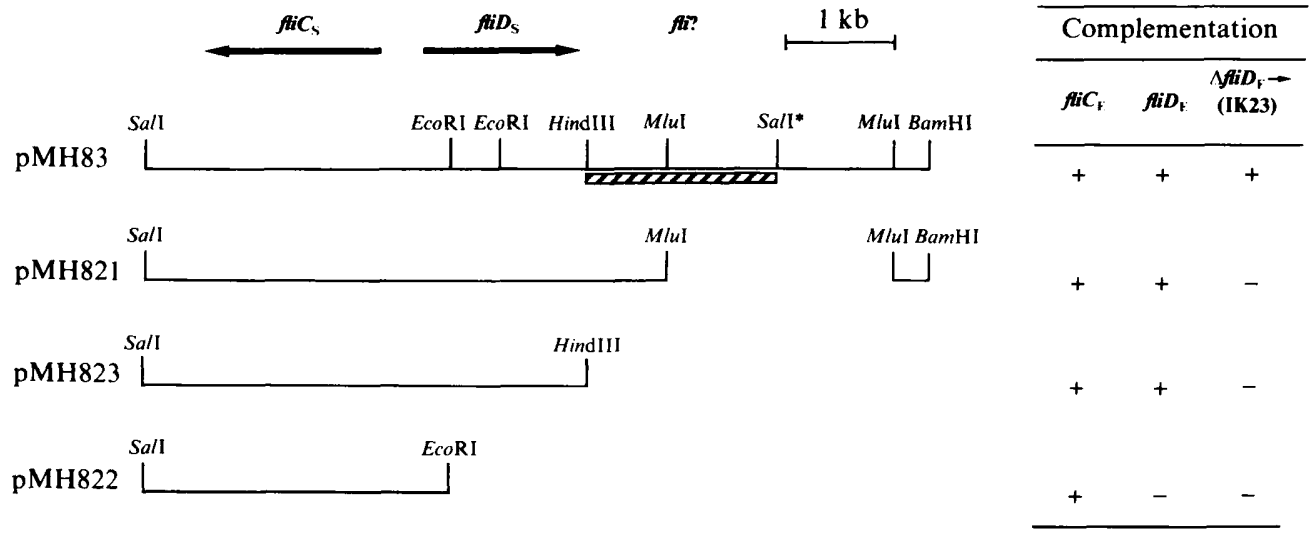

Fig. 5. Ability of various plasmids containing $S$. typhimurium inserts to complement $E$. coli mutants defective in $f i C_{\mathrm{E}}, f i D_{\mathrm{E}}$ or $f i D_{\mathrm{E}}$ and beyond (strain IK23, see Fig. $3 b$ ), the purpose being to test whether or not the DNA beyond fiD is flagellar-related (fi?). Complementation was judged by swarming ability and flagellation. Sal ${ }^{*}$ represents the site of deletion of a small SalI-SalI fragment during the original construction of pMH83. The HindIII-SaII* fragment (hatched box) was used for sequencing the region beyond $f i D_{\mathrm{S}}$

Plasmid pMH83 (Fig. 5) contains about $6 \mathrm{~kb}$ of contiguous $S$. typhimurium DNA between its two SalI sites; the second site, indicated as $\mathrm{SalI}^{*}$, represents a deletion of a small SalI-SalI fragment after which the insert continues for another $1.3 \mathrm{~kb}$. The region up to the $\mathrm{SalI}^{*}$ site contains $f l C_{\mathrm{S}}, \mathrm{fiD}_{\mathrm{S}}$ and $1.7 \mathrm{~kb}$ beyond the $3^{\prime}$ end of $f i D_{\mathrm{S}}$. Plasmids pMH821 and pMH823, derived from pMH83, retain $f i C_{\mathrm{S}}$ and $f i D_{\mathrm{S}}$ intact but have had material downstream deleted. The deletion in pMH821 begins at a MluI site about 750 bp beyond the terminus of $f i D_{\mathrm{s}}$, while that in pMH823 begins at the HindIII site just beyond $f i D_{\mathrm{S}}$. Plasmid pMH822 has an even larger deletion starting at the first EcoRI site within $f i D_{\mathrm{S}}$.

pMH83 was able to complement not only mutants with defects in $f i C_{\mathrm{E}}$ and $f i D_{\mathrm{E}}$, but also strain IK 23 (Fig. 5). In contrast, pMH821 and pMH823 were able to complement the $f i C_{\mathrm{E}}$ and $f i D_{\mathrm{E}}$ mutants, but not IK23. As expected, pMH822 complemented the $f i C_{\mathrm{E}}$ mutant, but not the $f i D_{\mathrm{E}}$ mutant. High-intensity dark-field light microscopy (Macnab, 1976) showed that lack of swarming was a consequence of lack of flagellation. Thus the $S$. typhimurium information necessary to restore flagellation to IK23 includes not only $\mathrm{fiD}_{\mathrm{S}}$ itself but DNA extending beyond it by at least $750 \mathrm{bp}$. Since the complementation analysis was between $S$. typhimurium as donor and $E$. coli as recipient, we concluded that information necessary for flagellation exists beyond $f i D$ in both species, and therefore proceeded to characterize this part of the chromosome in more detail.

\section{Characterization of fliD and its downstream region in E. coli}

Only a partial sequence of $f i D_{\mathrm{E}}$ exists, obtained by Hanafusa et al. (1989) in the course of a study of the adjacent $f i C_{\mathrm{E}}$ operon; the sequence terminates at the BamHI site at bp 460 (Fig. 2). To characterize $f i D_{\mathrm{E}}$ and the flagellum-related DNA beyond it, we cloned the 2.3 kb BamHI-MluI fragment from pIK1001 into M13 phage. Using ExolII deletion derivatives, the fragment was sequenced in its entirety in both directions. We also used a synthetic primer to sequence through the BamHI site and verify that our sequence was contiguous to that of Hanafusa et al. (1989).

The open reading frame continues for $950 \mathrm{bp}$ beyond the BamHI site (Fig. 6) and, on the basis of comparison with $f i D_{\mathrm{S}}$ (Homma et al., 1990a), clearly corresponds to $f i D_{\mathrm{E}}$. Following the $f i D_{\mathrm{E}}$ coding region there is a gap of $24 \mathrm{bp}$ before an open reading frame of 408 bp (ORF1), a TGATG overlap, a second open reading frame of $363 \mathrm{bp}$ (ORF2), a gap of $77 \mathrm{bp}$, and a partial open reading frame, [ORF], that extends to the limit of the sequenced fragment. Following ORF2 and extending slightly into [ORF] there is a pronounced inverted repeat sequence.

Fig. 6 (facing page). DNA sequence in the vicinity of the $f i D$ operon of $E$. coli, and deduced amino acid sequences of the $f i D_{\mathrm{E}}, f i S_{\mathrm{E}}$, and $f i T_{\mathrm{E}}$ products. In the text, fiS and fiT are initially referred to as ORF1 and ORF2. The sequence prior to the BamHI site derives from Szekely \& Simon (1983) and Hanafusa et al. (1989). Start and stop codons, putative -35 and -10 promoter sequences, putative ribosome binding sites (S-D, Shine-Dalgarno sequence) and restriction sites referred to in the text are shown with underlining. Arrows below the non-coding region beyond $f i T_{\mathrm{E}}$ mark an inverted repeat that may be a transcription termination sequence for the $f i D_{\mathrm{E}}$ operon. [ORF] is a partial open reading frame, unrelated to flagellation, that extends to the MluI site in Fig. 2(a). 
1 ATTCCCGCTA TTAAAAAAAA CAATTAAACG $\frac{\text { TAAACTTTGC GCAATTCAGA CCGATAACCC CGGTATTCGT TTTACGTGTC GAAAGATAAA AGGAAATCGC }}{\text { fiD-35 } 10}$ FiD start

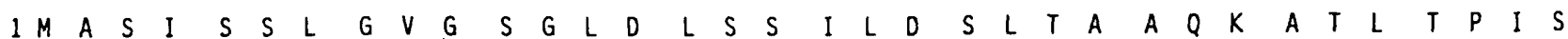
101 ATGGCAAGTA TITCATCGCT GGGAGTCGgG TCAGGTCTGG ATTTAAGTTC CATCCTTGAT AGCCTCACCG CCGCGCAAAA AGCGACGCTA ACCCCCATTT $\begin{array}{llllllllllllllllllllllllllllllllllll}35 & N & Q & Q & S & S & F & T & A & K & L & S & A & Y & G & T & L & K & S & A & L & T & T & F & Q & T & A & N & T & A & L & S & K & A\end{array}$ 201 CAAATCAGCA ATCGTCGTTT ACCGCTAAAC TTAGCGCCTA CGGTACGCTG AAAAGCGCGC TGACGACTTT CCAGACCGCC AATACTGCAT TGTCTAAAGC $\begin{array}{llllllllllllllllllllllllllllllllllll}68 & D & L & F & S & A & T & S & T & T & S & S & T & T & A & F & S & A & T & T & A & G & N & A & I & A & G & K & Y & T & I & S & V & T\end{array}$ 301 CGATCTTTTT TCCGCCACCA GCACCACCAG CAGCACCACC GCGTTCAGTG CCACCACTGC GGGTAACGCC ATCGCCGGGA AATACACCAT CAGCGTCACC

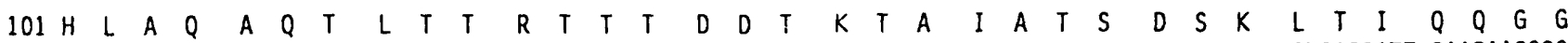
401 CATCTGGCGC AGgCGCAAAC CCTGACCACG CGCACCACCA CAGACGATAC GAAAACGGCG ATCGCCACCA GCGACAGTAA ACTCACCATT CAACAAGGCG $\begin{array}{lllllllllllllllllllllllllllllllllllllllll}135 & D & K & D & P & I & T & I & D & I & S & A & A & N & S & S & L & S & G & I & R & D & A & I & N & N & A & K & A & G & V & S & A & S\end{array}$ 501 GCGACAAAGA TCCGATTACC ATTGATATCA GCGCGGCTAA CTCATCGTTA AGCGgGATCC GTGATGCCAT CAACAACGCA AAAGCAGGCG TAAGCGCAAG

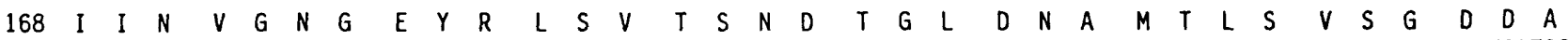
601 CATCATTAAC GTGGGTAACG GTGAATATCG TCTGTCAGTC ACATCAAATG ACACCGGCCT TGATAATGCG ATGACACTCT CGGTCAGCGG TGATGATGCG $\begin{array}{lllllllllllllllllllllllllllllllllllll}201 & L & Q & S & F & M & G & Y & D & A & S & A & S & S & N & G & M & E & V & S & V & A & A & Q & N & A & Q & L & T & V & N & N & V & A & I\end{array}$ 701 CTACAAAGTT TTATGGGCTA TGACGCCAGT GCCAGCAGCA ACGGTATGGA GGTCTCGGTT GCCGCCCAGA ATGCGCAGCT GACAGTCAAC AACGTCGCCA $\begin{array}{llllllllllllllllllllllllllllllllllll}235 & E & N & S & S & N & T & I & S & D & A & L & E & N & I & T & L & N & L & N & D & V & T & T & G & N & Q & T & L & T & I & T & Q & D\end{array}$ 801 TCGAGAACAG CAGCAACACC ATCAGCGACG CGCTGGAAAA CATCACCCTG AACCTGAACG ATGTCACCAC GGGCAACCAG ACGCTAACCA TCACTCAGGA

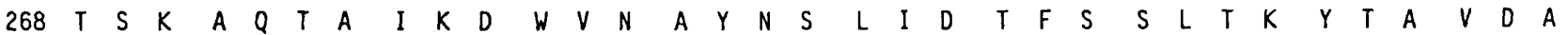
901 CACCTCCAAA GCGCAAACGG CGATTAAAGA CTGGGTGAAT GCCTACAACT CGCTAATAGA TACCTTCAGC AGCCTGACCA AATACACCGC CGTAGATGCG

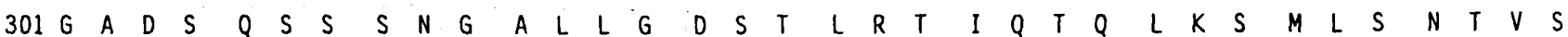
1001 GGAGCTGATA GCCAGAGTTC TAGCAATGGT GCACTGCTCG GCGACTCCAC GCTGCGGACG ATTCAGACGC AGTTGAATC GATGCTGAGT AATACCGTCA

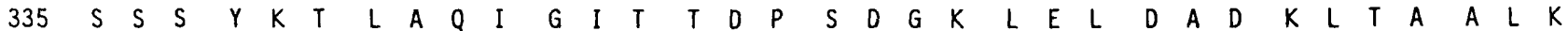
1101 GTTCTTCCAG CTATAAAACG TTGGCGCAGA TTGGTATCAC GACCGATCCC AGCGATGGCA AACTGGAACT GGATGCCGAC AAACTCACCG CTGCACTGAA

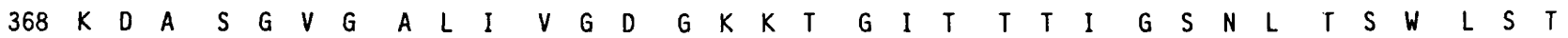
1201 AAAAGATGCC AGCGGCGTAG GTGCATTGAT TGTTGGCGAT GGTAAAAAAA CCGGCATCAC GACCACCATC GGCAGCAACC TGACCAGTTG GCTTTCGACA $\begin{array}{llllllllllllllllllllllllllllllllllll}401 & T & G & I & I & K & A & A & T & D & G & V & S & K & T & L & N & K & L & T & K & D & Y & N & A & A & S & D & R & I & D & A & Q & V & A\end{array}$ 1301 ACGGGCATTA TTAAAGCCGC TACCGATGGC GTTAGTAAGA CCCTGAATAA ATTAACTAAA GACTACAACG CCGCCAGCGA TCGCATTGAT GCGCAGGTCG

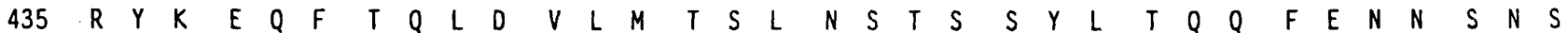
1401 CTCGCTACAA AGAACAATT ACCCAACTGG ACGITITAAT GACCTCGTTA AACAGCACCA GCAGCTACTT AACGCAGCAG TTCGAAACA ACAGTAATTC

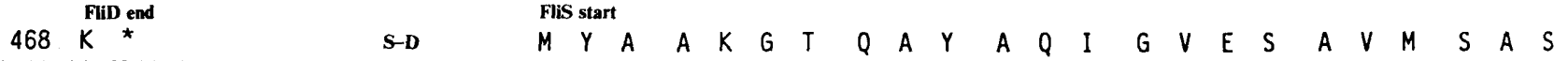

1501 CAAGTAAGCA ATATTCATCG GGAGACAGGT CATGTACGCG GCAAAAGGCA CCCAGGCCTA TGCACAAATT GGCGTCGAAA GCGCCGTAAT GAGCGCCAGC

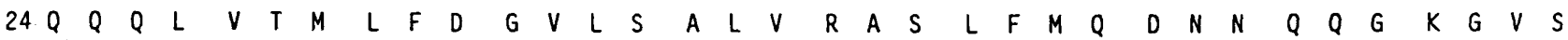
1601 CAGCAGCAGC TGGTCACCAT GCTATTTGAT GGAGTGCTGA GCGCACTGGT TAGAGCGAGC CTGTTTATGC AGGACAACAA TCAGCAAGGC AAAGGCGTCT

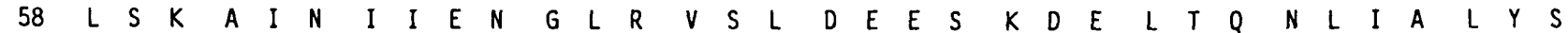

1701 CTTTGTCAAA AGCGATCAAC ATCATTGAGA ACGGACTGCG GGTGAGTCTT GATGAAGAGA GCAAAGACGA ACTAACCCAA AACTTGATTG CTCTTTATAG

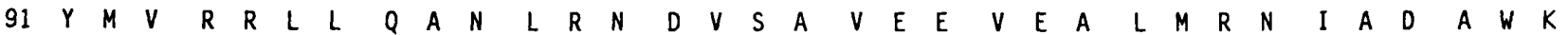
1801 CTATATGGTC AGgCGCTTGC TGCAAGCCAA TTTACGCAAC GATGTCTCCG CAGTCGAAGA AGTGGAAGCA TTAATGCGCA ATATTGCCGA TGCCTGGAAA 1 S-D Fils end/FilT start

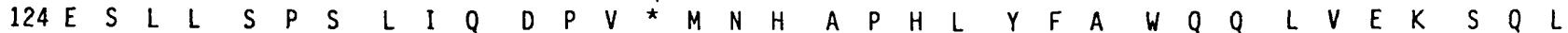
1901 GAGTCGTTAC TCTCCCCTTC TTTGATTCAG GACCCAGTCT GATGAACCAT GCACCGCATT TATATTTCGC CTGGCAACAA CTCGTCGAAA AAAGCCAGCT

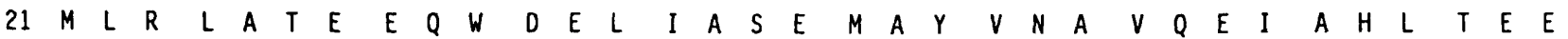
2001 CATGTTACGC CTGGCAACGG AAGAACAATG GGACGAACTC ATCGCCAGCG AAATGGCGTA TGTGAATGCG GTGCAGGAGA TTGCACATTT GACTGAAGAG

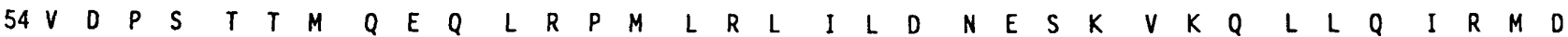
2101 GTTGACCCGT CCACCACGAT GCAGGAGCAG CTCCGCCCGA TGCTGCGCCT GATTCTCGAC AACGAAAGCA AGGTAAAGCA GTTATTACAG ATTCGGATGG

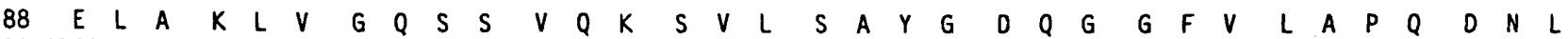
2201 ATGAACTGGC GAAACTGGTC GGTCAGTCAT CGGTGCAAAA ATCGGTGTTA AGTGCCTATG GCGATCAGGG CGGCTTTGTG CTGGCTCCGC AGGATAACCT $121 \stackrel{\text { FiT end }}{\mathrm{F}}$ औ

2301 CTITIGAATC TGAATGAGTC GATGGCTCGC GAATAATCCG ATTACGGCTA CGCTTCTAAT GTTCCCCTTG AATGGAGTCG AAGAATGCGT AATCCCACGC

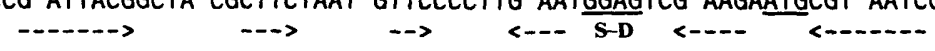




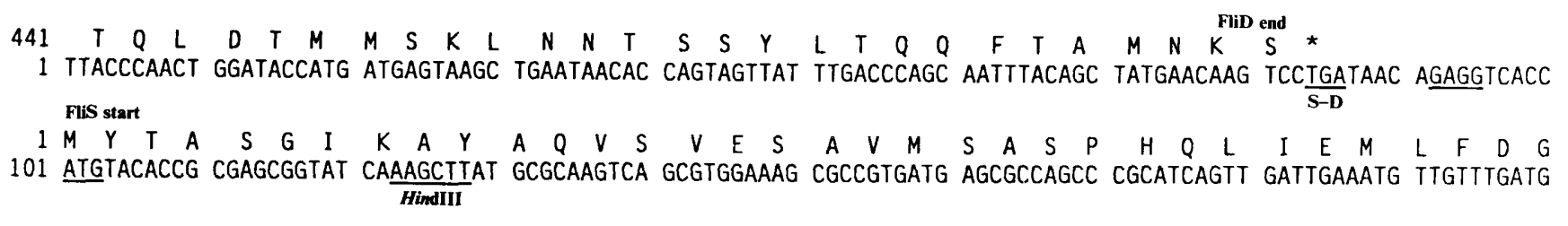

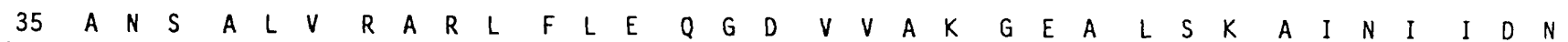
201 GCGCGAATAG CGCTCTGGTG CGCGCTCGCC TGTITTTAGA ACAAGGCGAT GTTGTCGCGA AAGGTGAAGC GTTAAGCAAA GCCATCAATA TTATCGATAA

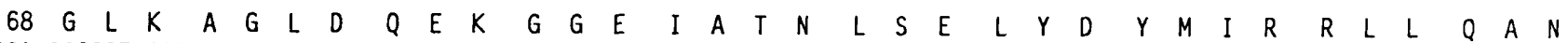
301 CGgGCTGAAA GCCGGCCTCG ATCAGgAAAA AGgCGgTGAG ATTGCGACGA ATCTTTCCGA GCTATACGAC TATATGATTC GCCGTTTACT GCAGGCTAAT

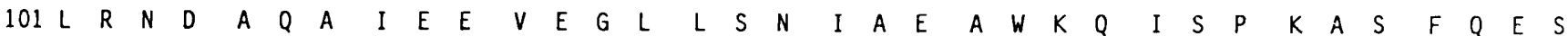
401 TTGCGTAACG ACGCTCAGGC CATCGAAGAA GTGGAaggGt TACTCAGCAA TATTGCAGAA GCCTGGAAGC AGATTTCACC GAAAGCATCT TTCCAGGAGT

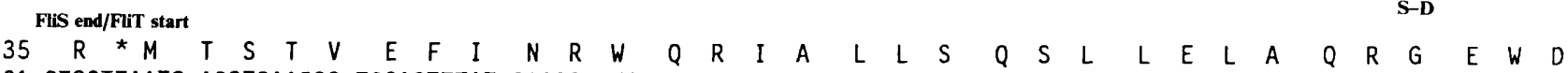
501 CTCGTIAATG ACCTCAACCG TGGAGTTTAT CAACCGTTGG CAGCGTATTG CGCTGCTCAG TCAATCGCTG CTTGAACTTG CGCAGCGAGG TGAATGGGAT

$\begin{array}{llllllllllllllllllllllllllllllllllllllllllllllll}32 & L & L & L & Q & Q & E & V & S & Y & L & Q & S & I & E & T & V & M & E & K & Q & T & P & P & G & I & T & R & S & I & Q & D & M & V & A\end{array}$ 601 CTCTTACTGC AACAAGAGGT CTCCTATCTG CAAAGTATTG AAACGgTGAT GGAAAAGCAA ACTCCACCGG GCATTACGCG AAGTATTCAG GATATGGTCG

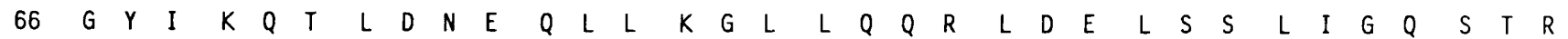
701 CCGGATACAT CAAACAAACG CTGGACAATG AGCAGCTCCT GAAAGGGCTG CTGCAACAGC GACTGGATGA ACTGAGTAGT TTGATCGGAC AATCCACCCG

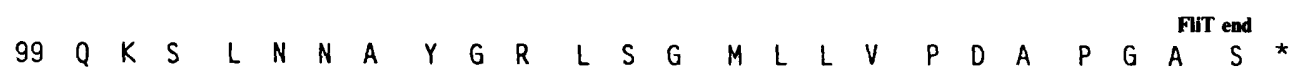
801 CCAAAAATCA CTCAACAACG CGTATGGCCG TCTTTCCGGT ATGTTACTCG TGCCAGATGC GCCTGGCGCC TCATAATATT TTCCCGTCTC GTATGAAAAT 1 TCTTCCATAC TCCAGAGGTC GGCTAAACGA CTTCTGGAGC ACGGAAGATG AAAAACCCCA CGTTA...
Fig. 7. DNA sequence in the vicinity of $f i S$ and $f i T$ of $S$. typhimurium, and deduced amino acid sequences of their products. The
complete sequence of $f i D_{\mathrm{S}}$, and the sequence beyond it to the HindIII site shown, was known (Homma et al., 1990a). Start and stop
codons, putative -35 and -10 promoter sequences, putative ribosome binding sites (S-D, Shine-Dalgarno sequence) and restriction
sites referred to in the text are shown with underlining. Arrows below the non-coding region beyond $f i T_{\mathrm{S}}$ mark an inverted repeat that
may be a transcription termination sequence for the $f i D_{\mathrm{S}}$ operon. [ORF] is a partial open reading frame, unrelated to flagellation and
closely similar to [ORF] of $E$. coli $\left(\right.$ Fig. 6 ), that extends to the $S a l I^{*}$ site in Fig. 5 .

Consideration of the sequence beyond $f i D_{\mathrm{E}}$ will be postponed until the corresponding sequence of $S$. typhimurium has been described in the following section.

\section{Characterization of the region downstream of fliD in S. typhimurium}

The sequence of $f i D_{\mathrm{S}}$ has already been described (Homma et al., 1990a), along with a small amount of $3^{\prime}$ flanking sequence up to the HindIII site shown in Fig. 5. We have now subcloned the HindIII-Sall* fragment of pMH83 and sequenced it, and also sequenced through the HindIII site of pMH83 to establish contiguity.

The DNA following $f i D_{\mathrm{S}}$ (Fig. 7) exhibits a similar pattern to that for $E$. coli: a gap of $14 \mathrm{bp}$ following the $f i D_{\mathrm{S}}$ coding region, an open reading frame of $405 \mathrm{bp}$ (ORF1), a TAATG overlap, a second open reading frame of 366 bp (ORF2), a gap of 71 bp containing a pronounced inverted repeat sequence, and a partial open reading frame, [ORF], that extends to the limit of the sequenced fragment.
The deduced amino acid sequences of the partial open reading frame, [ORF], in the two species are very similar (14\% difference for the $\mathrm{N}$-terminal 139 residues for which sequence is available in both species vs. $23 \%$ difference at the nucleotide level; data not shown), arguing that it does indeed correspond to the $5^{\prime}$ portion of a gene. Since its disruption does not impair flagellation or motility, it is presumably not part of the flagellar gene system, and is being investigated separately (M. Raha and R. M. Macnab, unpublished data).

\section{Identification of $O R F 1$ and $O R F 2$ as flagellar genes}

In both species, ORF1 and ORF2 have strong potential ribosome binding sites, and were assessed as coding regions at the $96 \%$ confidence level by the program TESTCODE (Fickett, 1982). The fact that the deduced amino acid sequences for corresponding open reading frames in the two species (i.e. ORF1 $1_{E}$ vs. ORF $1_{S}$, and $O R F 2_{E}$ vs. ORF2 $2_{S}$ ) show significant identity (see below) 


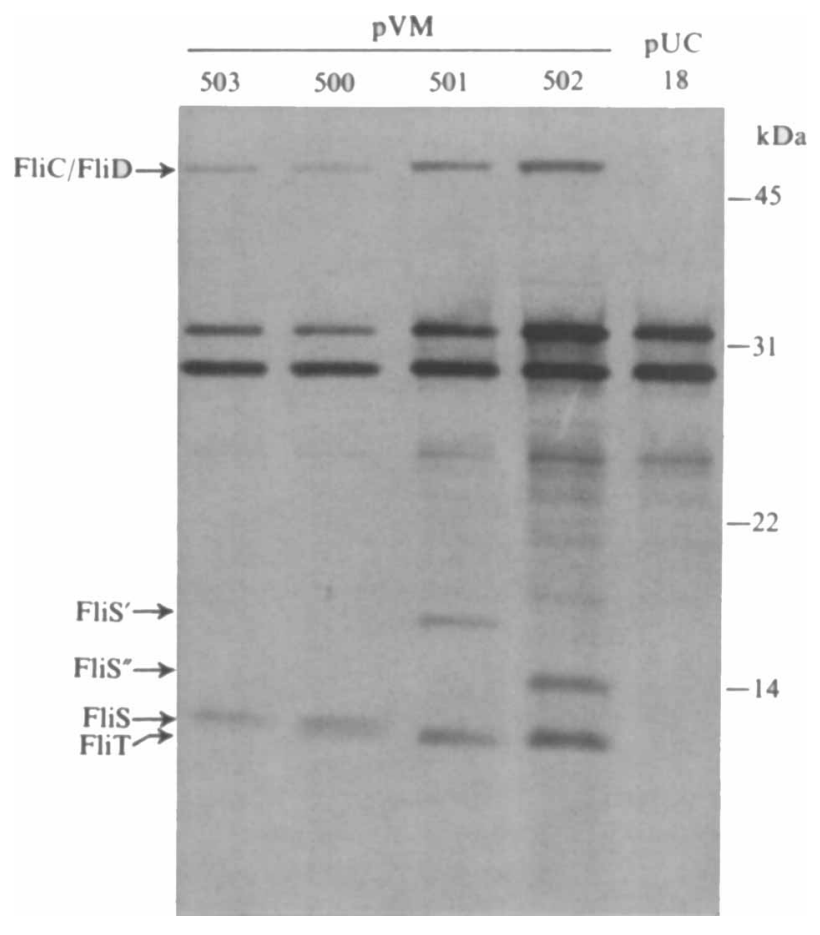

Fig. 8. Identification of $\mathrm{FliS}_{\mathrm{S}}$ and $\mathrm{FliT}_{\mathrm{S}}$ produced in radiolabelled minicells transformed with the plasmids shown, which contain a Sall fragment that covers the $S$. typhimurium fiCDST region. pVM500 contains the wild-type version, pVM501 and pVM502 have in-frame linker insertions into fi $_{\mathrm{S}}$ (to generate products FliS' and FliS"), and pVM503 has fli $_{\mathrm{s}}$ truncated. Flagellar proteins and molecular mass markers are indicated. further supports the conclusion that they are authentic coding regions.

We already knew that ORF2 played a role in flagellar structure or assembly, based on the complementation properties of pMH821 (Fig. 5), in which it is truncated at the MluI site (Fig. 7). However, the complementation behaviour of pMH823 did not permit any conclusion concerning ORF1, since ORF2 was also lacking. We wished therefore to disrupt ORF1 without affecting ORF2. This was done by cloning the SalI fragment of pMH83 into pBR322 and inserting an in-frame XhoI linker into the Eco47III site in ORF1 to give pVM702. We also generated a plasmid, pVM703, in which ORF2 was truncated as a result of deletion from the MluI site in ORF2 through to a SphI site in the vector. pVM702 and pVM703 both complemented mutants JA11 $\left(\Delta f i C_{\mathrm{E}}:: k a n\right)$ and $\mathrm{YK} 1101\left(f i D_{\mathrm{E}}\right)$, but were unable to complement IK23. Failure to complement as judged on swarm plates was subsequently shown by high-intensity dark-field light microscopy to stem from failure to restore flagellation.

We conclude that both ORF1 and ORF 2 are necessary for flagellation and show below that they are expressed genes. In the revised nomenclature for the flagellar genes of $E$. coli and $S$. typhimurium (Iino et al., 1988), genes in former region III were assigned the symbol $f i$ followed by extensions $A, B$, etc. The last known $f i$ gene being $f i R$, we have named the two newly discovered genes $f i S$ and $f i T$, respectively.

\section{Identification of the fliS and fiT gene products}

We next wished to verify that $f i S$ and $f i T$ were expressed and to identify their products. Plasmid pVM500 is a pUC18-based plasmid containing the $S a l I$ insert of $S$. typhimurium DNA from pMH83, which includes $f i C D S T_{\mathrm{s}}$. From it, we constructed three derivatives: pVM501 and pVM502 with in-frame EcoRI and XhoI linkers, respectively, inserted into the Eco47III site in $f i S_{\mathrm{S}}$; and pVM503 with $f i T_{\mathrm{S}}$ truncated at the MluI site. These plasmids were used to identify the products of $f i S_{\mathrm{S}}$ and $f i T_{\mathrm{S}}$ in a minicell expression system (Fig. 8). Proteins corresponding to $\mathrm{FliC}_{\mathbf{S}}$ and $\mathrm{FliD}_{\mathrm{S}}$ were detected with all four plasmids as a poorly resolved doublet at an apparent molecular mass of about $52 \mathrm{kDa}$. With pVM500, two further proteins were seen with apparent molecular masses of about 12 and $11 \mathrm{kDa}$, respectively. With pVM501 and pVM502, the $12 \mathrm{kDa}$ band was replaced by one with a higher apparent molecular mass; with pVM503, the $11 \mathrm{kDa}$ band was absent. We conclude that $f i S_{\mathrm{S}}$ and $f i T_{\mathrm{S}}$ were being expressed, with the $12 \mathrm{kDa}$ and $11 \mathrm{kDa}$ bands corresponding to $\mathrm{FliS}_{\mathrm{S}}$ and $\mathrm{FliT}_{\mathrm{s}}$, respectively.

\section{Deduced sequences of the FliS and FliT proteins}

FliS of E. coli and S. typhimurium show a moderate degree of conservation ( $60 \%$ identity) uniformly distributed throughout the sequence (Fig. 9b). FliT is rather 


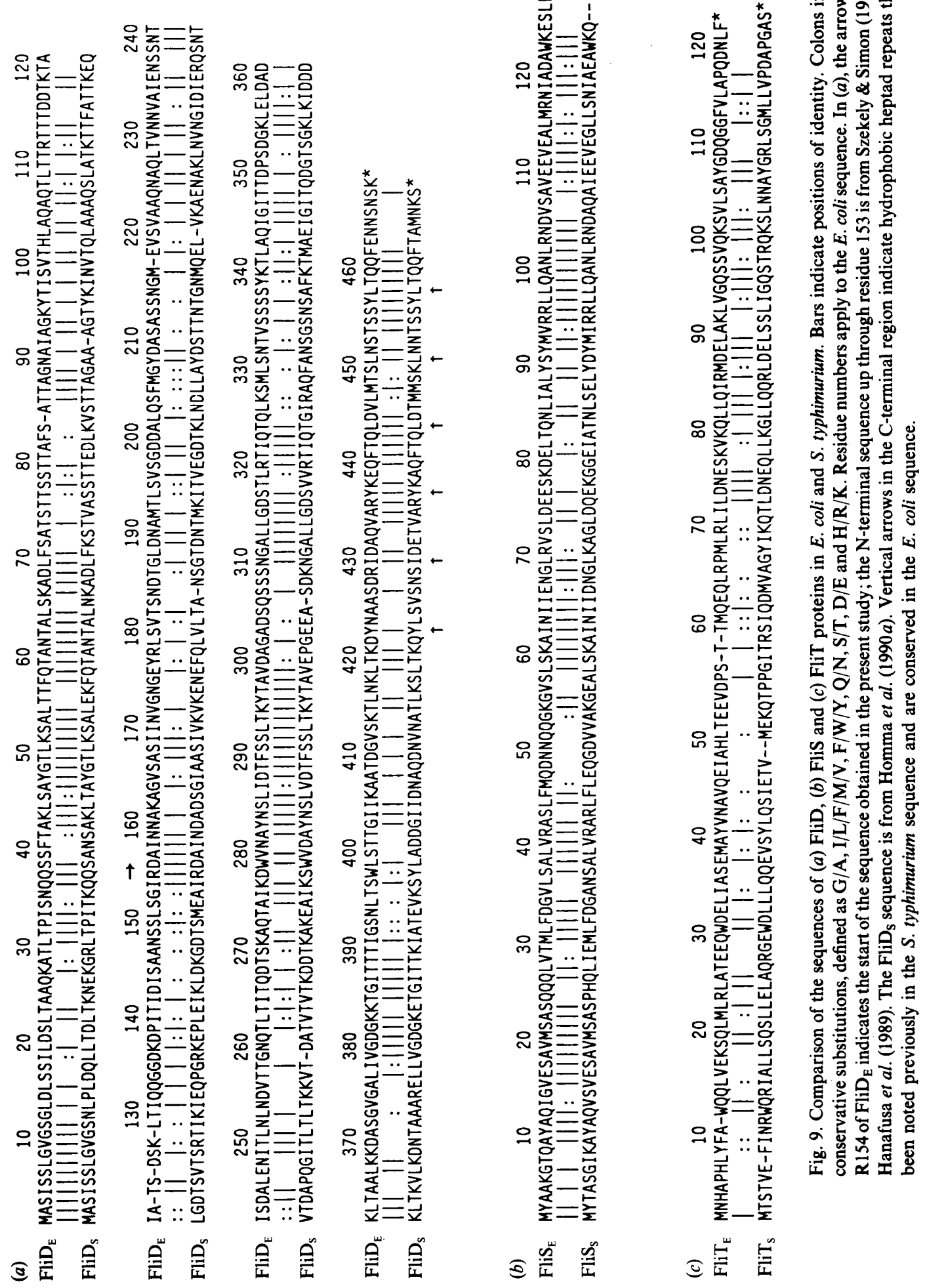


weakly conserved by comparison with other flagellar proteins whose sequences have been described in both species, with an overall identity of only $34 \%$ (Fig. $9 c$ ). The $\mathrm{N}$-terminus is especially divergent, with the first 71 residues showing only $23 \%$ identity.

The deduced molecular masses of the proteins are $14933 \mathrm{Da}\left(\mathrm{FliS}_{\mathrm{E}}\right), 14670 \mathrm{Da}\left(\mathrm{FliS}_{\mathrm{S}}\right), 13813 \mathrm{Da}\left(\mathrm{FliT}_{\mathrm{E}}\right)$ and $13689 \mathrm{Da}\left(\mathrm{FliT}_{\mathrm{S}}\right)$, in reasonable agreement with the apparent molecular masses found in the minicell analysis. Neither FliS nor FliT are predicted to have a preponderance of any single secondary structural motif, nor do their hydropathy profiles suggest that they are integral membrane proteins (data not shown). Both are moderately acidic. Although their general properties are similar to each other, they do not appear to be related to each other at the sequence level. Nor are they similar to any of the other flagellar proteins whose sequence is known. Finally, no obvious homologues emerged in comparisons against the NBRF protein database or the translated GenBank database.

FliD is a member of the family of proteins that constitute the axial structure and are exported by the flagellum-specific export pathway (Macnab, 1990). The sequences of the proteins in this family have a number of features in common (Homma et al., 1990a,b). None of these were evident in FliS or FliT.

\section{Comparison of FliD of E. coli and S. typhimurium}

The deduced amino acid sequence of FliD $_{\mathrm{E}}$ and the previously published sequence of FliD $_{\mathrm{S}}$ (Homma et al., $1990 a$ ) are compared in Fig. 9(a). Overall the two are moderately similar ( $52 \%$ identity), with the termini showing the highest degree of similarity. The central region is quite divergent, except for a short region of identity around residue 158 .

FliD $_{\mathbf{S}}$ has various properties, which are thought to be important in terms of inter-subunit interactions in the axial structure (Homma et al., 1990a, b). These are shared by FliD $_{\mathrm{E}}$. (i) Unlike the other axial proteins, FliD lacks a consensus ANNLAN motif in its N-terminal region. (ii) A partial match (SNL) to a consensus SGL motif near the $\mathrm{N}$-terminus of other axial proteins was seen in FliD ${ }_{S}$ and is seen as the full consensus in FliD $\mathrm{E}_{\mathrm{E}}$. (iii) The $\mathbf{N}$-terminal region lacks the hydrophobic heptad repeats that are seen in the other axial proteins. (iv) The $\mathrm{N}$-terminal region contains proline residues, unlike the other axial proteins. (v) The central region contains proline residues, as is the case with the other axial proteins. (vi) The C-terminal region lacks proline residues, as is also true of the other axial proteins. (vii) The C-terminal region contains hydrophobic heptad repeats, as is true of the other axial proteins; the repeats are in phase when the $\mathrm{FliD}_{\mathrm{E}}$ and $\mathrm{FliD}_{\mathrm{S}}$ sequences are aligned by the algorithm of Lipman \& Pearson (1985).

\section{Discussion}

In spite of the large amount of classical genetics that has gone into an understanding of the flagellar gene system, analysis at the molecular level can still produce surprises. The results of the present study illustrate this point, since they require that the long-standing view of one of the major fiagellar regions of the chromosomes of both $E$. coli and $S$. typhimurium, region III, be substantially modified.

\section{Sub-division of flagellar region III}

Region III of the flagellar regulon of $E$. coli and $S$. typhimurium contains a large intervening region, between $f i D$ and $f i E$, that had not been recognized until now. Most of it is unnecessary for flagellar structure, assembly or function, since a mutant with a $5.4 \mathrm{~kb}$ deletion was still well-flagellated and motile. The mutant also swarmed normally, indicating that chemotaxis was unimpaired. In view of this, we have redefined flagellar region III as two regions, IIIa and IIIb. Region IIIa contains the genes $f i A B C D$ and also two newly discovered genes, $f i S$ and $f i T$; region IIIb contains the genes fliEFGHIJKLMNOPQR (Fig. 10).

The $5.4 \mathrm{~kb} M l u \mathrm{I}-X b a \mathrm{I}$ fragment of $E$. coli must constitute almost the entire non-flagellar region, which probably begins immediately after the end of $f i T$ (about $500 \mathrm{bp}$ before the $M l u \mathrm{I}$ site), and can extend no further beyond the $X b a I$ site than $700 \mathrm{bp}$, where the $3^{\prime}$ end of the leftward facing $f i E_{\mathrm{E}}$ gene is found (Müller et al., 1992) . Thus its total extent is probably about $6.6 \mathrm{~kb}$. In $S$. typhimurium, the corresponding estimate is lower, about $4.2 \mathrm{~kb}$; the reason for this difference is not clear.

Regions IIIa and IIIb, though separated, are still very close together on the overall scale of the chromosome. We suspect that they (and possibly region II also) originally constituted a contiguous region and that chromosomal rearrangements, which must have occurred prior to the divergence of $E$. coli and $S$. typhimurium, resulted in their interruption.

It is interesting that regions IIIa and IIIb differ in the types of genes and operons they contain. The four previously known genes in region IIIa (Fig. 10) are all, in one way or another, related to the flagellar filament protein, flagellin: fit encodes a flagellum-specific sigma factor for the flagellin operon and other late operons

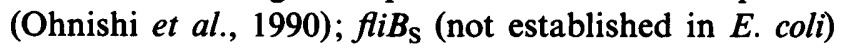
encodes an enzyme that post-translationally modifies flagellin (Konno et al., 1976); fiC encodes flagellin itself (Silverman \& Simon, 1973a; Horiguchi et al., 1975); and 


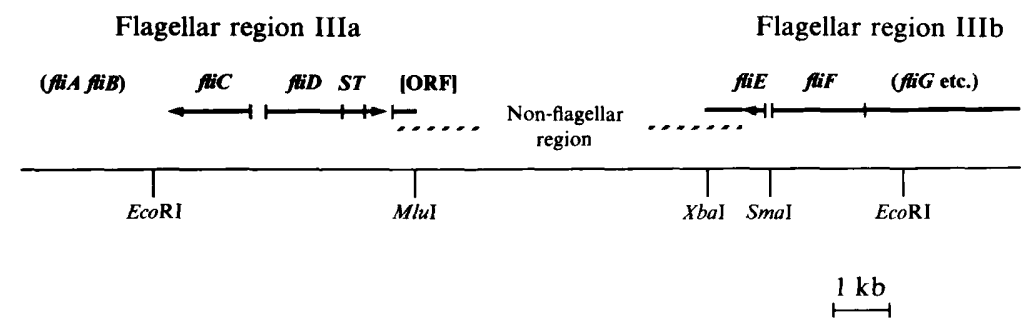

\begin{abstract}
Fig. 10. Current knowledge concerning the fliC-fiF portion of former flagellar region III of E. coli, which on the basis of this study has been subdivided into regions IIIa and IIIb with the $f i D$ and $f i E$ operons separated by a large distance; a similar situation exists for $S$. typhimurium. Operons are indicated by arrows, with gene boundaries within them indicated by vertical bars. In region IIIa, $f i C$ is preceded by $f i A$ and (in $S$. typhimurium) fliB; in region IIIb, fliF is followed by $f i G H I J K L M N O P Q R$ (cf. Fig. 1). fliS and $f i T$ are newly discovered flagellar genes, which represent a continuation of the fiD operon. The first gene in region IIIb is fiE, whose precise location and polarity has been determined recently (Müller et al., 1992). [ORF] is a partial open reading frame that appears to be unrelated to flagellar function and extends to the limit of the sequenced fragment at the $M l u I$ site shown. Between the $M l u I$ and $X b a I$ sites there is $5 \cdot 4$ kb of DNA, which can be deleted without affecting flagellar structure or function. It represents the minimum extent of the non-flagellar region, which probably extends from the $3^{\prime}$ end of $f i T$ to the $3^{\prime}$ end of $f i E$ (hatched line).
\end{abstract}

fiD encodes the filament capping protein (Homma et al., 1985), which is essential for filament assembly. The two newly discovered region IIIa genes, $f l i S$ and $f i T$, are of unknown function but apparently belong to the same operon as $f i D$ (see below) and so may be functionally related.

In contrast, the 14 genes in region IIIb are involved in structures assembled earlier than the flagellar filament: For example, fiE encodes a basal-body protein (Müller $e t$ al., 1992); fliF encodes the basal-body M-ring protein (Homma et al., 1987); fliG, fiM and fiN encode the flagellar switch proteins (Parkinson et al., 1983; Yamaguchi et al., 1986); and fiI is an ATPase homologue that may be involved in the process of export and assembly of flagellar proteins (Vogler et al., 1991). Although the specific function of many of the other region IIIb genes is unknown, the mutant phenotype is generally a lack of any detectable flagellar structure.

Thus one can broadly distinguish region IIIa genes ( $f i A B C D S T$ ) and region IIIb genes ( fiEFGHIJKLM$N O P Q R)$ in a functional sense, as being related to the filament and to structures preceding the filament, respectively.

This is reflected also in the patterns of gene expression. Kutsukake et al. (1990) have described the flagellar regulon as a hierarchy, with operons at three levels. Of the four operons in region IIIa, two ( $f i C$ and $f i D$ ) definitely belong to class 3 (late flagellar operons) and a third ( $f i B)$ probably does also, considering that its product is an enzyme that covalently modifies flagellin. The fourth operon ( $f i A)$, though itself belonging to class 2 (middle flagellar operons), serves to regulate expression of class 3 operons. The three operons in region IIIb, containing $f i E, f i F-f i K$, and $f i L-f i R$, respectively
(Komeda, 1986; Kutsukake et al., 1988), all belong to class 2 .

\section{The fliD operon and the functions of FliS and FliT}

fiD is transcribed separately from other known flagellar genes (Komeda et al., 1980; Kutsukake et al., 1988) and is preceded by a strong flagellar-specific promoter (Szekely \& Simon, 1983; Hanafusa et al., 1989; Homma et al., 1990a). The available evidence argues strongly that $f i D, f i S$ and $f i T$ constitute an operon: (i) the three genes are closely spaced or even overlapping; (ii) there are no recognizable promoter sequences prior to $f i S$ or $f i T$; (iii) there are no recognizable transcription termination sequences following $f i D$ or $f i S$; (iv) there is a substantial non-coding region following $f i T$, and it contains a pronounced inverted repeat sequence, which is likely to represent the transcription termination sequence of the fiD operon; (v) disruption of the open reading frame following $f i T$ does not affect flagellar function. Detailed analysis of the transcription of the fliD operon is in progress elsewhere (K. Kutsukake, personal communication).

The $f i D$ gene product is known to be a protein located at the distal end of the flagellar filament, which enables exported subunits of flagellin to assemble rather than being lost to the medium (Homma et al., 1984, 1985; Ikeda et al., 1987).

What about the roles of FliS and FliT? Two lines of evidence suggest that they may be regulatory rather than structural. First, the genes appear to belong in the same operon as $f i D$ and should therefore be subject to the same transcriptional control. One would therefore expect their products to be needed at a similar (late) place in the 
assembly pathway as FliD (Homma et al., 1984). Yet their deduced amino acid sequences show no resemblance to FliD or to any other members of the axial family (Homma et al., 1990a, b). Nor are there any proteins with the molecular masses of FliS or FliT in the external portion of the flagellum, which has been characterized carefully (Ikeda et al., 1987). Thus the evidence argues against $f i S$ and $f i T$ being structural genes.

Second, the fliD operon exerts a poorly understood regulatory effect, such that defects cause over-expression of other late operons (Kutsukake et al., 1990); a repressor-like activity, RflA, has therefore been attributed to this operon. It is not clear how fliD itself, as a structural gene, could exert such an effect. If, however, the operon contained regulatory genes, the phenomenon would be easier to understand, at least in principle. Interestingly, we noted that plasmids with $f i D$ and fis intact but with $f i T$ truncated produced motile transformants on $f i D$ hosts much more rapidly than when $f i T$ was intact on the plasmid; conversely, if $f i S$ was disrupted, transformants appeared much more slowly. This could be a reflection of positive and negative regulatory activities associated with $f i S$ and $f i T$, respectively. However, the situation must be more complex than this, since the mutant phenotype associated with $f i T$ is non-flagellate.

Defined mutations in $f l i D, f i S$ and $f i T$ and an examination of their effects on the levels of expression of late operons are needed to further understand the regulatory role of the fliD operon; experiments along these lines are in progress $(K$. Kutsukake, personal communication). Once the relative contributions of each of these genes to regulation has been established, mechanistic studies can be initiated.

\section{FliD as a member of the axial family of proteins}

We have recently analysed the members of a structurally related family of flagellar proteins of $S$. typhimurium, namely those that comprise the flagellar rod, hook, hook-filament junction, filament and filament cap (Homma et al., 1990a, b). Of these, the protein of the filament cap, FliD $_{\mathrm{S}}$, distinguished itself from the rest in that its $\mathrm{N}$-terminal region contained prolines, lacked hydrophobic heptad repeats, and showed little sequence similarity to any of the other members. Its C-terminal region conformed better to the general description provided by the family in that it contained hydrophobic heptad repeats. The sequence of FliD $_{E}$ reinforces these conclusions.

We had suggested, based on our own results and those of others (Namba et al., 1989; Aizawa et al., 1990;
Vonderviszt et al., 1990), that side-by-side interactions of amphipathic $\alpha$-helices formed from $\mathrm{N}$-terminal and $\mathrm{C}$ terminal sequence might be important in inter-subunit interactions in the axial structure. We also noted that the unique location of FliD, at the tip of the axial structure, might be the reason for the nonconformity of its $\mathrm{N}$ terminal sequence to the patterns seen with all of the other axial proteins. A corollary of this would be that the $\mathrm{C}$-terminal sequence of a given axial protein subunit would be involved primarily in interactions with subunits on its proximal side (i.e. closer to the cell surface) and, conversely, the $\mathrm{N}$-terminal sequence would be involved in interactions with subunits to the distal side (i.e. closer to the tip of the organelle).

The information that was available at the time concerning FliD $_{E}$ (the N-terminal 153 residues) indicated a rather high degree of divergence from $\mathrm{FliD}_{\mathrm{S}}$, and we postulated this might be because the $\mathrm{N}$-terminus was not constrained by inter-subunit interactions. However, both termini are now seen to be more divergent than in the case of the other two axial proteins where the sequence is known in both species, namely, flagellin (Joys, 1985; Kuwajima et al., 1986) and hook protein (Homma et al., 1990a; J. Rosenberg, I. Kawagishi, D. DeRosier \& R. Macnab, unpublished data). Thus while it remains true that the $\mathrm{N}$-terminus of FliD has different properties from those of the other axial proteins, it is not significantly less conserved between the two species than is the C-terminus, which does have the characteristics of the other axial proteins.

The internal portion of the sequence of FliD is the most divergent. This has emerged as a general feature of the axial proteins, and is thought to reflect a domain at the outer radius of the axial structure.

\section{Function of the non-flagellar region}

Unlike most eukaryotic cells, bacteria have an extremely compact genome and so a region of about $6 \mathrm{~kb}$ seems too large to be merely a spacer, and presumably contains several genes. One indication that this is the case is the observation that, shortly beyond the $3^{\prime}$ end of $f i T$, there is a partial open reading frame that appears to be the $5^{\prime}$ end of an authentic gene, since the deduced amino acid sequences in $E$. coli and $S$. typhimurium show a high level of identity. Investigation of this putative gene and of the remainder of the non-flagellar region is in progress, with results that suggest that at least part of the region is involved in polysaccharide metabolism (M. Raha \& R. M. Macnab, unpublished data). It will be interesting to compare the region in $E$. coli and $S$. typhimurium to establish what features have been conserved in the time since the two species diverged. 
We thank S.-I. Aizawa, J. Asaka, B. Bachmann, Y. Komeda, J. S. Parkinson, M. Simon and S. Yamaguchi for strains and plasmids. We are grateful to the following undergraduate students who contributed to various aspects of this study: Julia Charles, Anthony Iafrate and Edward Kim. We thank H. Yamada for assistance with the DNA hybridization. Computer database searches were carried out at the Rosenstiel Basic Medical Sciences Center, Brandeis University, during a sabbatical visit by R.M.M. This work was supported by USPHS grants AI12202 and GM40335 (to R. M.M.) and a fellowship from the Deutsche Forschungsgemeinschaft (to V.M.).

\section{References}

Aizawa, S.-I., Vonderviszt, F., Ishima, R. \& Akasaka, K. (1990). Termini of Salmonella flagellin are disordered and become organized upon polymerization into flagellar filament. Journal of Molecular Biology 211, 673-677.

BACHMANN, B. J. (1990). Linkage map of Escherichia coli K-12, edition 8. Microbiological Reviews 54, 130-197.

Bartlett, D. H. \& Matsumura, P. (1984). Identification of Escherichia coli Region III flagellar gene products and description of two new flagellar genes. Journal of Bacteriology 160, 577-585.

Bartlett, D. H., Frantz, B. B. \& Matsumura, P. (1988). Flagellar transcriptional activators FlbB and FlaI: gene sequences and $5^{\prime}$ consensus sequences of operons under FlbB and FlaI control. Journal of Bacteriology 170, 1575-1581.

Dean, G. E., Macnab, R. M., Stader, J., Matsumura, P. \& Burks, C. (1984). Gene sequence and predicted amino acid sequence of the motA protein, a membrane-associated protein required for flagellar rotation in Escherichia coli. Journal of Bacteriology 159, 991-999.

FeinberG, A. P. \& Vogelstein, B. (1983). A technique for radiolabelling DNA restriction endonuclease fragments to high specific activity. Analytical Biochemistry 132, 6-13.

FICKETT, J. W. (1982). Recognition of protein coding regions in DNA sequences. Nucleic Acids Research 10, 5303-5318.

GilleN, K. L. \& HuGhes, K. T. (1991). Molecular characterization of $f l g M$, a gene encoding a negative regulator of flagellin synthesis in Salmonella typhimurium. Journal of Bacteriology 173, 6453-6459.

hanafusa, T., Sakai, A., Tominaga, A. \& Enomoto, M. (1989). Isolation and characterization of Escherichia coli hag operator mutants whose hag 48 expression has become repressible by a Salmonella H1 repressor. Molecular and General Genetics 216, 44-50.

Homma, M., KuTsukake, K., IINo, T. \& Yamaguch, S. (1984). Hookassociated proteins essential for flagellar filament formation in Salmonella typhimurium. Journal of Bacteriology 157, 100-108.

Homma, M., KUTSUKaKe, K. \& IINO, T. (1985). Structural genes for flagellar hook-associated proteins in Salmonella typhimurium. Journal of Bacteriology 163, 464-471.

Homma, M., Aizawa, S.-I., Dean, G. E. \& Macnab, R. M. (1987). Identification of the M-ring protein of the flagellar motor of Salmonella typhimurium. Proceedings of the National Academy of Sciences of the United States of America 84, 7483-7487.

Homma, M., DeRosier, D. J. \& MaCnab, R. M. (1990a). Flagellar hook and hook-associated proteins of Salmonella typhimurium and their relationship to other axial components of the flagellum. Journal of Molecular Biology 213, 819-832.

Homma, M., Kutsukake, K., Hasebe, M., Iino, T. \& Macnab, R. M. $(1990 b)$. FlgB, FlgC, FlgF and FlgG. A family of structurally related proteins in the flagellar basal body of Salmonella typhimurium. Journal of Molecular Biology 211, 465-477.

Horiguchi, T., Yamaguchi, S., YAo, K., TAIRA, T. \& InNo, T. (1975). Genetic analysis of $\mathrm{H} 1$, the structural gene for phase-1 flagellin in Salmonella. Journal of General Microbiology 91, 139-149.

Iino, T., Komeda, Y., Kutsukake, K., Macnab, R. M., Matsumura, P., Parkinson, J. S., Simon, M. I. \& Yamaguchi, S. (1988). New unified nomenclature for the flagellar genes of Escherichia coli and Salmonella typhimurium. Microbiological Reviews 52, 533-535.
IKedA, T., Homma, M., IINo, T., Asakura, S. \& KamiYa, R. (1987) Localization and stoichiometry of hook-associated proteins within Salmonella typhimurium flagella. Journal of Bacteriology 169, 1168 1173.

Jones, C. J., Homma, M. \& MaCnab, R. M. (1989). L-, P-, and M-ring proteins of the flagellar basal body of Salmonella typhimurium: gene sequences and deduced protein sequences. Journal of Bacteriology 171, 3890-3900.

JoYs, T. M. (1985). The covalent structure of the phase-1 flagellar filament protein of Salmonella typhimurium and its comparison with other flagellins. Journal of Biological Chemistry 260, 15758-15761.

Kihara, M., Homma, M., KutsukaKe, K. \& MaCNab, R. M. (1989) Flagellar switch of Salmonella typhimurium: gene sequences and deduced protein sequences. Journal of Bacteriology 171, 3247-3257.

KIM, M. C. (1989). Molecular characterization and regulation of the gene expression of fhB operon in Escherichia coli. $\mathrm{PhD}$ thesis. University of Illinois, Chicago, USA.

KofoID, E. C. \& PARKInson, J. S. (1991). Tandem translation starts in the cheA locus of Escherichia coli. Journal of Bacteriology 173, 21162119.

Kohara, Y., Axiyama, K. \& Isono, K. (1987). The physical map of the whole $E$. coli chromosome: application of a new strategy for rapid analysis and sorting of a large genomic library. Cell 50, 495-508.

KOMEDA, Y. (1986). Transcriptional control of flagellar genes in Escherichia coli K-12. Journal of Bacteriology 168, 1315-1318.

Komeda, Y., KuTSUKAKe, K. \& IINO, T. (1980). Definition of additional flagellar genes in Escherichia coli K12. Genetics 94, 277290.

Komeda, Y., ONO, N. \& KAGAWA, H. (1984). Synthesis of flagellin and hook subunit protein in flagellar mutants of Escherichia coli K12. Molecular and General Genetics 194, 49-51.

KONDOH, H. (1977). Isolation and characterization of nondefective transducing lambda bacteriophages carrying fla genes of Escherichia coli K-12. Journal of Bacteriology 130, 736-745.

Konno, R., Fujita, H., Horiguchi, T. \& Yamaguchi, S. (1976). Precise position of the $\mathrm{nml}$ locus on the genetic map of Salmonella. Journal of General Microbiology 93, 182-184.

Krikos, A., MUtoh, N., Boyd, A. \& Simon, M. I. (1983). Sensory transducers of $E$. coli are composed of discrete structural and functional domains. Cell 33, 615-622.

Kuo, S. C. \& Koshland, D. E., JR (1986). Sequence of the flaA (cheC) locus of Escherichia coli and discovery of a new gene. Journal of Bacteriology 166, 1007-1012.

Kutsukake, K., Ohya, Y., Yamaguchi, S. \& Iino, T. (1988). Operon structure of flagellar genes in Salmonella typhimurium. Molecular and General Genetics 214, 11-15.

KuTSUKAKE, K., OHYA, Y. \& IINo, T. (1990). Transcriptional analysis of the flagellar regulon of Salmonella typhimurium. Journal of Bacteriology 172, 741-747.

Kuwajma, G., AsaKa, J.-I., Fujiwara, T., Fujiwara, T., Node, K. \& KONDOH, E. (1986). Nucleotide sequence of the hag gene encoding flagellin of Escherichia coli. Journal of Bacteriology 168, 1479-1483.

Lipman, D. J. \& Pearson, W. R. (1985). Rapid and sensitive protein similarity searches. Science 227, 1435-1441.

MACNAB, R. M. (1976). Examination of bacterial flagellation by darkfield microscopy. Journal of Clinical Microbiology 4, 258-265.

MACNAB, R. M. (1987a). Flagella. In Escherichia coli and Salmonella typhimurium: Cellular and Molecular Biology, vol. 1, pp. 70-83. Edited by F. C. Neidhardt, J. Ingraham, K. B. Low, B. Magasanik, M. Schaechter \& H. E. Umbarger. Washington, DC: American Society for Microbiology.

MACNAB, R. M. (1987b). Motility and chemotaxis. In Escherichia coli and Salmonella typhimurium: Cellular and Molecular Biology, vol. 1, pp. 732-759. Edited by F. C. Neidhardt, J. Ingraham, K. B. Low, B. Magasanik, M. Schaechter \& H. E. Umbarger. Washington, DC: American Society for Microbiology.

MaCnAB, R. M. (1990). Genetics, structure, and assembly of the bacterial flagellum. Symposia of the Society for General Microbiology 46, 77-106.

Malakooti, J., Komeda, Y. \& Matsumura, P. (1989). DNA sequence analysis, gene product identification, and localization of flagellar motor components of Escherichia coli. Journal of Bacteriology 171, 2728-2734. 
Müller, V., Jones, C. J., Kawagishi, I., Aizawa, S.-I. \& MaCnab, R. M. (1992). Characterization of the fiE genes of Escherichia coli and Salmonella typhimurium and identification of the FliE protein as a component of the flagellar hook-basal body complex. Journal of Bacteriology 174, 2298-2304.

MUTOH, N. \& SimON, M. I. (1986). Nucleotide sequence corresponding to five chemotaxis genes in Escherichia coli. Journal of Bacteriology 165, 161-166.

Namba, K., Yamashita, I. \& Vonderviszt, F. (1990). Structure of the core and central channel of bacterial flagella. Nature, London 342 , 648-654.

OHNishi, K., KutsuKake, K., SUZuki, H. \& IIno, T. (1990). Gene fliA encodes an alternative sigma factor specific for flagellar operons in Salmonella typhimurum. Molecular and General Genetics 221, 139-147.

Parkinson, J. S., Parker, S. R., Talbert, P. B. \& Houts, S. E. (1983) Interactions between chemotaxis genes and flagellar genes in Escherichia coli. Journal of Bacteriology 155, 265-274.

SAmbrook, J., Fritsch, E. F. \& Maniatis, T. (1989). Molecular Cloning. A Laboratory Manual, 2nd edn. Cold Spring Harbor NY: Cold Spring Harbor Laboratory.

SANDERSON, K. E. \& Roth, J. R. (1988). Linkage map of Salmonella typhimurium, edition VII. Microbiological Reviews 52, 485-532.

Sanger, F., Nicklen, S. \& Coulson, A. R. (1977). DNA sequencing with chain-terminating inhibitors. Proceedings of the National Academy of Sciences of the United States of America 74, 5463-5467.

Silverman, M. \& Simon, M. (1973a). Genetic analysis of flagellar mutants in Escherichia coli. Journal of Bacteriology 113, 105-113.

Sil Verman, M. \& Simon, M. (1973b). Genetic analysis of bacteriophage Mu-induced flagellar mutants in Escherichia coli. Journal of Bacteriology 116, 114-122.

Silverman, M. \& Simon, M. (1974). Positioning flagellar genes in Escherichia coli by deletion analysis. Journal of Bacteriology 117, 7379.

Sil verman, M., Matsumura, P., Draper, R., Edwards, S. \& Simon,
M. I. (1976). Expression of flagellar genes carried by bacteriophage lambda. Nature, London 261, 248-250.

Stader, J., Matsumura, P., Vacante, D., Dean, G. E. \& Macnab, R. M. (1986). Nucleotide sequence of the Escherichia coli mot $B$ gene and site-limited incorporation of its product into the cytoplasmic membrane. Journal of Bacteriology 166, 244-252.

SUZUKI, T. \& KomedA, Y. (1981). Incomplete flagellar structures in Escherichia coli mutants. Journal of Bacteriology 145, 1036-1041.

SzeKely, E. \& Simon, M. (1983). DNA sequence adjacent to flagellar genes and evolution of flagellar-phase variation. Journal of Bacteriology 155, 74-81.

Vogler, A. P., Homma, M., Irikura, V. M. \& Macnab, R. M. (1991). Salmonella typhimurium mutants defective in flagellar filament regrowth and sequence similarity of FliI to $F_{0} F_{1}$, vacuolar, and archaebacterial ATPase subunits. Journal of Bacteriology 173, 35643572 .

Vonderviszt, F., Uedaira, H., Kidokoro, S.-I. \& NAMBa, K. (1990). Structural organization of flagellin. Journal of Molecular Biology 214, 97-104.

Wyman, A. R., Wolfe, L. B. \& Botstein, D. (1985). Propagation of some human DNA sequences in bacteriophage $\lambda$ vectors requires mutant Escherichia coli hosts. Proceedings of the National Academy of Sciences of the United States of America 82, 2880-2884.

Yamaguchi, S., IINo, T., HoriguchI, T. \& OHTA, K. (1972). Genetic analysis of $f a$ and mot cistrons closely linked to $\mathrm{H} 1$ in Salmonella abortusequi and its derivatives. Journal of General Microbiology $\mathbf{7 0}$, 59-75.

Yamaguchi, S., Fujita, H., Sugata, K., Taira, T. \& Iino, T. (1984). Genetic analysis of $\mathbf{H} 2$, the structural gene for phase-2 flagellin in Salmonella. Journal of General Microbiology 130, 255-265.

Yamaguchi, S., Fuitia, H., Ishihara, A., Aizawa, S.-I. \& Macnab, R. M. (1986). Subdivision of flagellar genes of Salmonella typhimurium into regions responsible for assembly, rotation, and switching. Journal of Bacteriology 166, 187-193. 